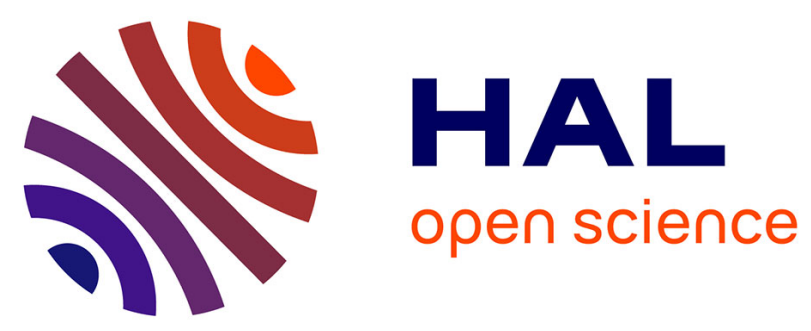

\title{
Giant congenital melanocytic nevus with vascular malformation and epidermal cysts associated with a somatic activating mutation in BRAF
}

Heather C. Etchevers, Christian Rose, Birgit Kahle, Helmuth Vorbringer, Frederic Fina, Pauline Heux, Irina Berger, Benjamin Schwarz, Stéphane Zaffran, Nicolas Macagno, et al.

\section{To cite this version:}

Heather C. Etchevers, Christian Rose, Birgit Kahle, Helmuth Vorbringer, Frederic Fina, et al.. Giant congenital melanocytic nevus with vascular malformation and epidermal cysts associated with a somatic activating mutation in BRAF. Pigment Cell and Melanoma Research, In press, 10.1111/pcmr.12685 . hal-01613153v2

\section{HAL Id: hal-01613153 \\ https://hal.science/hal-01613153v2}

Submitted on 16 Feb 2018

HAL is a multi-disciplinary open access archive for the deposit and dissemination of scientific research documents, whether they are published or not. The documents may come from teaching and research institutions in France or abroad, or from public or private research centers.
L'archive ouverte pluridisciplinaire HAL, est destinée au dépôt et à la diffusion de documents scientifiques de niveau recherche, publiés ou non, émanant des établissements d'enseignement et de recherche français ou étrangers, des laboratoires publics ou privés. 


\section{Giant congenital melanocytic nevus with vascular}

malformation and epidermal cysts associated with a somatic activating mutation in $B R A F$

Heather C. Etchevers ${ }^{1,}{ }^{,}$, Christian Rose ${ }^{2}$, Birgit Kahle ${ }^{3}$, Helmuth Vorbringer ${ }^{4}$, Frédéric Fina ${ }^{5}$, Pauline Heux ${ }^{1}$, Irina Berger ${ }^{6}$, Benjamin Schwarz ${ }^{1}{ }^{*}$, Stéphane Zaffran $^{1}$, Nicolas Macagno ${ }^{5,7}$, Sven Krengel ${ }^{80}$

Affiliations:

${ }^{1}$ Aix Marseille Univ, INSERM, UMR_S910, Génétique Médicale et Génomique Fonctionnelle, Marseille, France

${ }^{2}$ Dermatohistological Laboratory, Lübeck, Germany

${ }^{3}$ Department of Dermatology, University Hospital Lübeck, Germany

${ }^{4}$ Radiological group practice, Lübeck, Germany

${ }^{5}$ Department of Pathology, Hôpital de la Timone, APHM, Marseille, France

${ }^{6}$ Institut für Pathologie und Neuropathologie, Klinikum Kassel, Kassel, Germany

${ }^{7}$ Aix Marseille Univ, INSERM, UMR_S 911, CRO2, Marseille, France

${ }^{8}$ Dermatological group practice, Lübeck, Germany

${ }^{*}$ Current address: Department of Biology, University of Erlangen-Nürnberg,

Erlangen, Germany

${ }^{\square}$ Authors for correspondence.

E-mail : heather.etchevers@inserm.fr. INSERM UMR_S910 GMGF, Faculté de Médecine AMU, 27 boulevard Jean Moulin, 13005 Mārseille, France

E-mail : Sven.Krengel@uksh.de. Moislinger Allee 95, 23558 Lübeck, Germany

Other authors : rose@dermatohistologie-luebeck.de, birgit.kahle@uksh.de, email@drvorbringer.de, Frederic.FINA@ap-hm.fr, pauline.heux@univ-amu.fr, benjamin.schwarz@fau.de, stephane.zaffran@inserm.fr, Nicolas.MACAGNO@ap$\underline{\mathrm{hm} . \mathrm{fr}}$ 


\section{Summary}

Giant congenital melanocytic nevi may be symptomatically isolated, or syndromic. Associations with capillary malformations are exceptional, and development of epidermal cysts has not been described. A 71-year old patient with a giant congenital melanocytic nevus of the lower back, buttocks and thighs was asymptomatic except for unexpected hemorrhage during partial surgical excision years before. Blunt trauma at age 64 initiated recurrent, severe pain under the nevus; multiple large epidermal cysts then developed within it. Imaging and biopsy showed a large, non-pulsatile venous malformation intermingled with the deep nevus. A low-abundance, heterozygous BRAF c.1799T>A (p.V600E) mutation was present in both gluteal and occipital congenital nevi; additional mutations in NRAS, GNAQ, GNA11, HRAS or PIK3CA were undetectable. This is the first demonstration of a recurrent $B R A F$ mutation in multiple large congenital nevi from the same individual, confirming that this malformation can have multiple genetic origins. Early constitutive activation of BRAF can therefore cause unusual associations of giant nevi with vascular malformations, indicating that both pigment and endothelial cell physiology may be affected by mosaic RASopathies.

\section{Significance}

The molecular basis for an unusual, syndromic giant congenital melanocytic nevus turned out to be a constitutively active, post-zygotic BRAF c.1799T>A (p.V600E) mutation in both the primary and a distant nevus. After blunt trauma and inflammation in late adulthood, epidermal cysts then developed over, and a venous malformation became symptomatic under, the giant nevus. This observation enlarges the spectrum of congenital mosaic RASopathies to an 
additional new entity with potentially late symptomatic onset, the result of concurrently affected vascular and pigment cell development before birth.

Keywords: braf, mosaic, venous, malformation, neural crest

A 71-year-old, healthy male Caucasian, Fitzpatrick skin type II, presented with a reddish-brown, giant congenital melanocytic nevus (CMN, classified G1-S1-C1-R2N2-H1; Krengel, Scope, Dusza, Vonthein, \& Marghoob, 2012) involving the complete right gluteal area, parts of the left gluteal area and the lower back, the dorsal aspect of the right thigh and the right hip region (Figure 1A; also known as "bathing trunk" using the "6B" pattern definitions; Martins da Silva et al., 2017). The gluteal area showed soft, nodular thickening with black comedones and multiple yellowish cysts, measuring $1-3 \mathrm{~cm}$ (Figure 1B). On the proximal thigh, the CMN exhibited another soft, thickened area with relatively loose skin folds and small fibroma-like nodules. Hypertrichosis was present at the upper and lower borders of the nevus. An additional light-brown, medium-sized CMN of $8 \mathrm{~cm}$ in diameter was found in the occipital area (Figure 1C).

At age 51, part of the primary CMN was surgically excised. The operation led to severe hemorrhage, requiring blood transfusion. The CMN had otherwise only caused cosmetic impairment until age 64 , when the patient experienced a blunt trauma to the $\mathrm{CMN}$, immediately followed by strong pain radiating down the right leg, temporary loss of motor control and fever, resolving over several weeks. Similar episodes of pain and fever, often with urticarial rash, are recurrent. After the initial injury, cysts developed in the primary nevus only, discharging pus during the inflammatory episodes. Currently, symptomatic severity has diminished to periodic local swelling, cyst inflammation and discomfort. Episodes are reproducibly provoked by prolonged sitting, as when travelling. The most intense pain is reported within an elevated area of approximately $3 \times 15 \mathrm{~cm}$ 
within the CMN, to the right of the natal cleft. Blood samples from the first years of painful episodes showed increased C-reactive protein, but this became undetectable. Other routine laboratory parameters were normal.

DNA was extracted using standard methods from paraffin sections of biopsies of the gluteal and occipital nevi. Both were subjected to direct Sanger sequencing of NRAS exons 2 and 3, BRAF exon 15, GNAQ exons 4 and 5, GNA11 exons 4 and 5, HRAS exons 2 and 3, and PIK3CA exon 20. Minor heterozygosity was found in both forward and reverse orientations for BRAF at position c.1799T>A (p.V600E), but not for the other exons sequenced, in both tissue samples (Figure 1D, 1E). Results were reproduced in two distinct laboratories with fresh DNA extractions from both biopsies and subsequently confirmed by Droplet Digital ${ }^{\mathrm{TM}}$ PCR (ddPCR) as described (Fina et al., 2017; Figure 1F).

A biopsy from the right buttock contained a large infundibular cyst with a welldefined granular layer and unpigmented cords of monomorphous small melanocytes throughout the reticular dermis (Figure 2A, B). Tryptase immunohistochemistry showed that mastocytes were normally distributed and uncorrelated with the pruritis (not shown). A specimen from the earlier partial surgical excision of this CMN, before cyst development, showed multiple mediumto-large blood vessels intermingled with the nevus cell aggregates (Figure 3C). The occipital CMN was typical, with small round melanocytes and no epidermal cysts (Figure 2C). Within the primary nevus, immunohistochemistry specific to V600E-mutant BRAF showed constitutively active protein in most CMN cells, ranging from undetectable to moderate (Figure 2D). Accordingly, immunofluorescence against the phosphorylated form of Erk1/2 had diffuse-tostrong cytoplasmic intensity in individual nevocytes, with low levels overall (Figure 2E, F). 
Surprisingly, magnetic resonance (MR) imaging revealed a slow-flow vascular malformation (Figure $3 \mathrm{~A}$ ) consisting of dilated veins that penetrated and drained the thickened nevus region (Figure 3D, through an epidermal cyst). Dynamic MR angiography after two hours of sitting revealed several small signal-reduced tubular foci within the area, potentially thromboses or flow-void phenomena. Trials with aspirin or low molecular weight heparin could not preclude or abridge subsequent pain, which was thus not ascribed to thromboses. Even after onset, however, discomfort was relieved by oral ibuprofen. Duplex sonography showed a spongiotic vascular infiltration with reduced flow, beginning in the upper nevus (Figure 3B). Nevus venules showed a single layer of alpha-smooth muscle actin (aSMA)-expressing cells (Figure 3E). Confocal microscopy confirmed that smaller venules and capillaries had aSMA-positive pericytes in direct apposition to VEcadherin-expressing endothelium, of which some nuclei protruded into the lumen (Figure 3F, G).

We have presented a patient with giant CMN and unusual clinical, molecular and cellular features. Non-invasive imaging indicated an underlying, partially thrombotic venous malformation, where the abnormal vascular structures originated in the mid-dermis. Histology and immunofluorescence confirmed increased dermal microvascular density among mutant BRAF-expressing nevocyte aggregates, and normal mast cell count. Along with reported hemorrhage upon earlier surgery and later aggravation after trauma, these observations are compatible with previously undiagnosed congenital venous malformation.

Large cohorts of patients reported with large and giant CMN have not mentioned concomitant vascular malformations. A superficially similar condition, phakomatosis pigmentovascularis, is clinically and histologically distinguished by 
a combination of dermal melanocytosis and teleangiectatic vascular malformations, due to somatic GNA11 or GNAQ mutations (Thomas et al., 2016). Wu and co-authors (2008) described cases with CMN and "infantile hemangiomas" : three had a solitary vascular lesion in the vicinity of a small/medium CMN, a child with a S1-type LCMN also had six small lesions, and two had deep or segmental lesions associated with LCMN or GCMN in a distinct part of the body. Lovett et al. described two children who had a capillary malformation under their large CMN, associated with intense pruritus (Lovett et al., 2009). Chronic itch is often reported by large CMN patients, who also demonstrate significantly higher densities of cutaneous mast cells (Salgado et al., 2014). Our patient also developed an urticarial rash together with the painful episodes, but no eczematous skin changes nor increased mast cell density in his CMN at the time of biopsy.

Epidermal cysts have occasionally been reported within small CMN on the face (Joo, Kim, \& Kang, 2016) but association of multiple epidermal cysts with a giant CMN has never been described. The late onset and lone site points to the initial trauma as a precipitating factor. Local inflammatory phenomena accompanying the pain are reminiscent of the inflammation in solitary epidermal cysts or in hidradenitis suppurativa (Danby, Jemec, Marsch, \& von Laffert, 2013).

Most giant CMN genotyped and thus reported carry constitutively activating mutations in codon 61 of NRAS (Dessars et al., 2009; Kinsler et al., 2013; Salgado et al., 2015; D. Wu et al., 2011). However, multiple cases of large-to-giant CMN with V600 mutations in BRAF (Dessars et al., 2009; Salgado et al., 2015), as well as two BRAF-activating chromosomal translocations (Dessars et al., 2007), have also been described. As seen here and elsewhere, BRAF-mutated CMN of any size present few or no "satellite" disseminated nevi at or after birth (Salgado et al., 2015). Thus, evidence of recurrent mutations in distant sites of the same patient, 
confirming an equally causative role for BRAF as for NRAS in giant CMN, had never been presented. BRAF-mutated giant CMN patients have been reported to form significantly more frequent subcutaneous proliferative nodules (Salgado et al., 2015), although their melanoma risk is no higher than for giant CMN with activating NRAS mutations.

In conclusion, this is the first report of a patient with $B R A F$-mutated giant $C M N$ in whom a distant, medium-sized CMN carried the same mutation. In addition, extensive vascular malformation and epidermal cysts were associated with the giant CMN. The co-localization of melanocytic, epidermal, and vascular hyperplasia, but the low mutant allele load within both $C M N$, indicate that the initiating mutation may have occurred in a single progenitor cell of the migratory neural crest. Its descendants would then have exerted non-cell-autonomous effects in utero on surrounding tissues of both ectodermal and mesodermal origins, which only became symptomatic late in life.

\section{Acknowledgements}

Cell Signaling Technology: anti-phospho-ERK1/2 (4376) and anti-VE-cadherin (2500); Abcam: anti-tryptase (EPR8476 clone); Spring Bioscience: anti-BRAF V600E (VE1); Sigma-Aldrich: anti-aSMA (F3777); BioRad: ddPCR. Supported by grants from Nevus Outreach, Inc., Asociación Española de afectados por Nevus Gigante Congénito, Association du Naevus Géant Congénital, Naevus 2000 France-Europe, Caring Matters Now, the RE(ACT) Community and aid-in-kind from the BeHeard Rare Disease Science Challenge. We thank Dominique FigarellaBranger, Badis Hamadou, Joanna Ordioni, Michel Pucéat and Christos Zouboulis for their assistance and thoughtful discussion. 


\section{Figures}

Figure 1. A. Giant congenital melanocytic nevus (CMN) of the lower back, gluteal region and right thigh, classified G1-S1-C1-R2-N2-H1. B. Detail from box in A showing multiple epidermal cysts inside the nevus region. C. Second-largest CMN on occipital scalp, delimited by blue dashed line. D, E: Sanger sequencing of $B R A F$, demonstrating c.1799T>A (arrowheads; V600E) mutation in lesional tissue and in the occipital satellite nevus, respectively. F: Droplet Digital ${ }^{\mathrm{TM}}$ PCR was performed according to the manufacturer's protocol (Bio-Rad) using absolute quantification mode in QuantaSoft (version 1.7.4.0917, Bio-Rad). Threshold for positive amplification was determined based on the results of a no template control, mutant and wild-type cloning plasmids, and control genomic DNA. Fractional abundance was calculated as the proportion of mutant reads to the sum of mutant and wildtype reads, confirming a recurrent BRAF c.1799T>A (V600E) mutation in both lesions.

\section{Figure 2.}

A. Infundibular cyst within a biopsy of the gluteal CMN. B. Different section of same sample, showing blood vessels intermingled with cords of junctional and dermal melanocytes. C. Typical CMN histology in the occipital lesion. D. Specific immunoreactivity to BRAF V600E constitutively active protein in nevocytes (brown, arrowheads). E: Phosphorylated (p)ERK1/2, red, is present in numerous cells of dermal nevus (arrowheads) . F: Magnification of right quadrant of E, showing cytoplasmic pERK1/2 signal in nevocytes (arrowheads). A-C, hematoxylin-eosin stain. D, hematoxylin counterstain. E, F, DAPI counterstain. Scale bars: A: 1 mm; B, D, E: $50 \mu \mathrm{m}$; C: $100 \mu \mathrm{m} ; \mathrm{F}: 25 \mu \mathrm{m}$. 
Figure 3. A. T1-weighted MRI cross-section through entire lower pelvis showing slow-flow vascular malformation (yellow arrow) underlying the hyperintense nevus tissue of the buttocks( $R$, right; $L$, left). B. Duplex sonography showing spongiotic vascular malformation (darker areas) infiltrating CMN tissue (lighter areas). An exemplary vein (blue) measured $0.36 \mathrm{~cm}$ in diameter at $5.5 \mathrm{~cm}$ deep in plane of outline. C: Vascular nevus tissue from partial surgery of primary CMN two decades earlier, resulting in severe hemorrhage. D. T2-weighted MRI crosssection at different axial level of pelvis from $\mathbf{A}$, showing CMN (dotted outline) penetrated by vascular spaces and large epidermal cyst (asterisk). E. Lowmagnification immunofluorescence of aSMA (green) in venules of gluteal CMN. F. Confocal microscopy of microvascular malformation (arrow) with aSMA-positive pericytes (green) apposed to disorganized VE-cadherin-positive endothelium (red). G. Another venule in same section shows mix of DAPI-labelled endothelial nuclei (blue) with normal flat morphology but also with unusual shapes protruding into lumen (arrows). e: erythrocytes. Scale bars: C, E, $100 \mu \mathrm{m} ; \mathrm{F}, 20$ $\mu \mathrm{m} ; \mathrm{G}, 5 \mu \mathrm{m}$. 


\section{References}

Danby, F. W., Jemec, G. B. E., Marsch, W. C., \& von Laffert, M. (2013). Preliminary findings suggest hidradenitis suppurativa may be due to defective follicular support. British Journal of Dermatology, 168(5), 1034-1039. https://doi.org/10.1111/bjd.12233

Dessars, B., De Raeve, L. E., El Housni, H., Debouck, C. J., Sidon, P. J., Morandini, R., ... Heimann, P. (2007). Chromosomal translocations as a mechanism of BRAF activation in two cases of large congenital melanocytic nevi. The Journal of Investigative Dermatology, 127(6), 1468-70.

https://doi.org/10.1038/sj.jid.5700725

Dessars, B., De Raeve, L. E., Morandini, R., Lefort, A., El Housni, H., Ghanem, G. E., ... Heimann, P. (2009). Genotypic and gene expression studies in congenital melanocytic nevi: insight into initial steps of melanotumorigenesis. The Journal of Investigative Dermatology, 129(1), 13947. https://doi.org/10.1038/jid.2008.203

Fina, F., Barets, D., Colin, C., Bouvier, C., Nanni-Metellus, I., Ouafik, L. H., ... Figarella-Branger, D. (2017). Droplet digital PCR is a powerful technique to demonstrate frequent FGFR1 duplication in dysembryoplastic neuroepithelial tumors. Oncotarget, 8(2), 2104-2113.

https://doi.org/10.18632/oncotarget.12881

Joo, H. J., Kim, J. E., \& Kang, H. (2016). Congenital Melanocytic Nevus with Distinctive Nevus Cell Proliferation within Multiple Epidermal Cyst-Like Changes. Annals of Dermatology, 28(1), 123.

https://doi.org/10.5021/ad.2016.28.1.123

Kinsler, V. A., Thomas, A. C., Ishida, M., Bulstrode, N. W., Loughlin, S., Hing, S., ... Moore, G. E. (2013). Multiple congenital melanocytic nevi and 
neurocutaneous melanosis are caused by postzygotic mutations in codon 61 of NRAS. The Journal of Investigative Dermatology, 133(9), 2229-36. https://doi.org/10.1038/jid.2013.70

Krengel, S., Scope, A., Dusza, S. W., Vonthein, R., \& Marghoob, A. A. (2012). New recommendations for the categorization of cutaneous features of congenital melanocytic nevi. Journal of the American Academy of Dermatology, 68(3), 441-51. https://doi.org/10.1016/j.jaad.2012.05.043

Lovett, A., Maari, C., Decarie, J.-C., Marcoux, D., McCuaig, C., Hatami, A., ... Powell, J. (2009). Large congenital melanocytic nevi and neurocutaneous melanocytosis: one pediatric center's experience. Journal of the American Academy of Dermatology, 61(5), 766-74. https://doi.org/10.1016/j.jaad.2008.11.022

Martins da Silva, V. P., Marghoob, A., Pigem, R., Carrera, C., Aguilera, P., PuigButillé, J. A., ... Malvehy, J. (2017). Patterns of distribution of giant congenital melanocytic nevi (GCMN): The 6B rule. Journal of the American Academy of Dermatology, 76(4), 689-694. https://doi.org/10.1016/j.jaad.2016.05.042

Salgado, C. M., Basu, D., Nikiforova, M., Bauer, B. S., Johnson, D., Rundell, V., ... Reyes-Múgica, M. (2015). BRAF Mutations Are Also Associated with Neurocutaneous Melanocytosis and Large/Giant Congenital Melanocytic Nevi. Pediatric and Developmental Pathology, 18(1), 1-9.

https://doi.org/10.2350/14-10-1566-OA.1

Salgado, C. M., Silver, R. B., Bauer, B. S., Basu, D., Schmitt, L., Khakoo, Y., \& Reyes-Múgica, M. (2014). Skin of patients with large/giant congenital melanocytic nevi shows increased mast cells. Pediatric and Developmental Pathology, 17(3), 198-203. https://doi.org/10.2350/14-02-1444-OA.1

Thomas, A. C., Zeng, Z., Rivière, J.-B., O’Shaughnessy, R., Al-Olabi, L., St.-Onge, J., 
... Kinsler, V. A. (2016). Mosaic Activating Mutations in GNA11 and GNAQ Are Associated with Phakomatosis Pigmentovascularis and Extensive Dermal Melanocytosis. Journal of Investigative Dermatology, 136(4), 770-778. https://doi.org/10.1016/j.jid.2015.11.027

Wu, D., Wang, M., Wang, X., Yin, N., Song, T., Li, H., ... Zhao, Z. (2011). Lack of BRAF(V600E) mutations in giant congenital melanocytic nevi in a Chinese population. The American Journal of Dermatopathology, 33(4), 341-4. https://doi.org/10.1097/DAD.0b013e3181fb5bc7

Wu, P. A., Mancini, A. J., Marghoob, A. A., \& Frieden, I. J. (2008). Simultaneous occurrence of infantile hemangioma and congenital melanocytic nevus: Coincidence or real association? Journal of the American Academy of Dermatology, 58(2 SUPPL. 1), 16-22. https://doi.org/10.1016/j.jaad.2006.04.085 


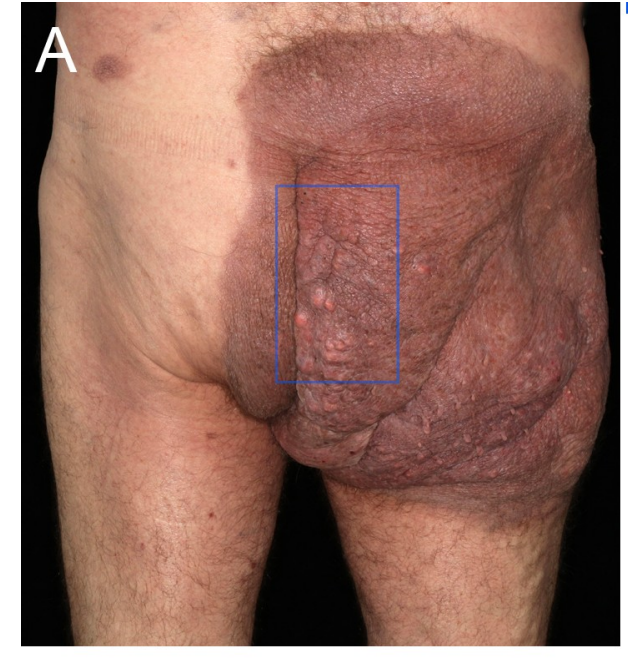

D

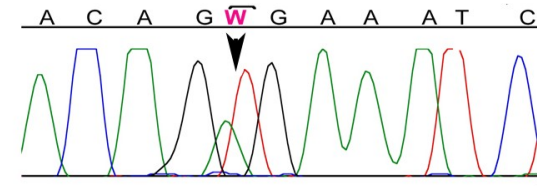

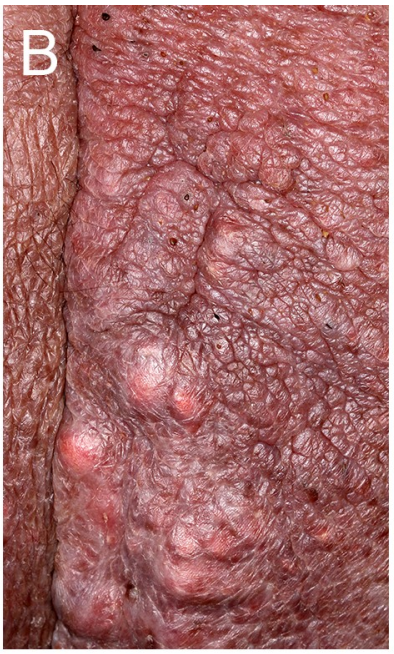

E

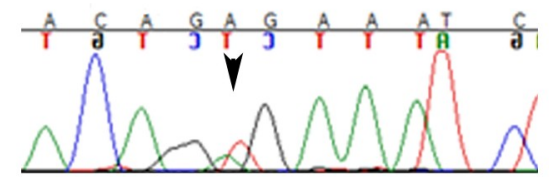

F

\begin{tabular}{|c|c|c|c|c|c|c|c|} 
Sample & $\begin{array}{c}\text { Copies } / \mu \mathrm{L} \\
\text { V600E }\end{array}$ & $\begin{array}{c}\text { Abs quant } \\
\text { V600E }\end{array}$ & $\begin{array}{c}\text { Copies } / \mu \mathrm{L} \\
\text { V600wt }\end{array}$ & $\begin{array}{c}\text { Abs quant } \\
\text { V600wt }\end{array}$ & $\begin{array}{c}\text { Accepted } \\
\text { Droplets }\end{array}$ & $\begin{array}{c}\text { Fractional } \\
\text { Abundance \% }\end{array}$ & $\begin{array}{c}\text { Mutation } \\
\text { call V600E }\end{array}$ \\
\hline Gluteal CMN & $11.9(10.4-13.3)$ & 257 & $38.1(35.5-40.7)$ & 815 & 25585 & $23.8(21.2-26.3)$ & mutated \\
\hline Occipital CMN & $1.9(1.4-2.6)$ & 43 & $138(133-143)$ & 2930 & 26406 & $1.4(1.0-1.8)$ & mutated
\end{tabular}




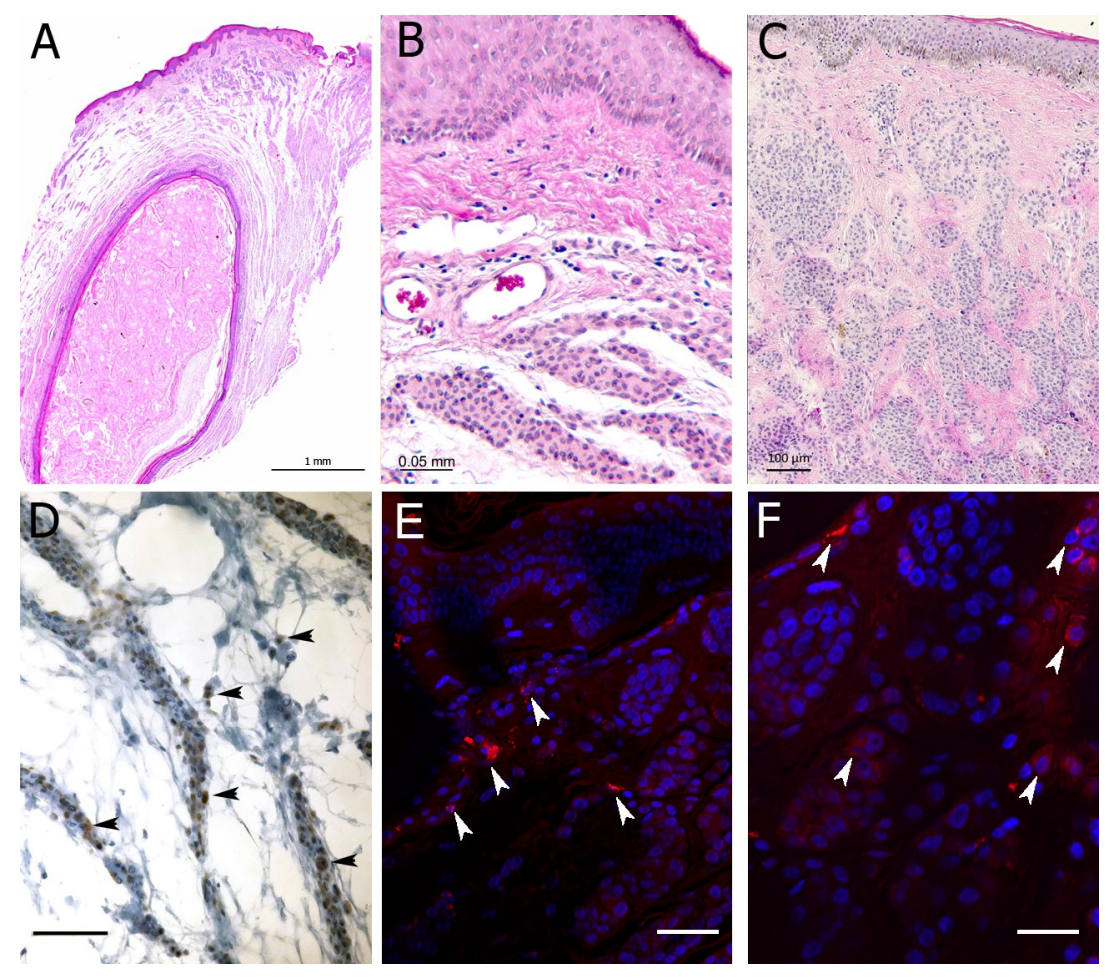



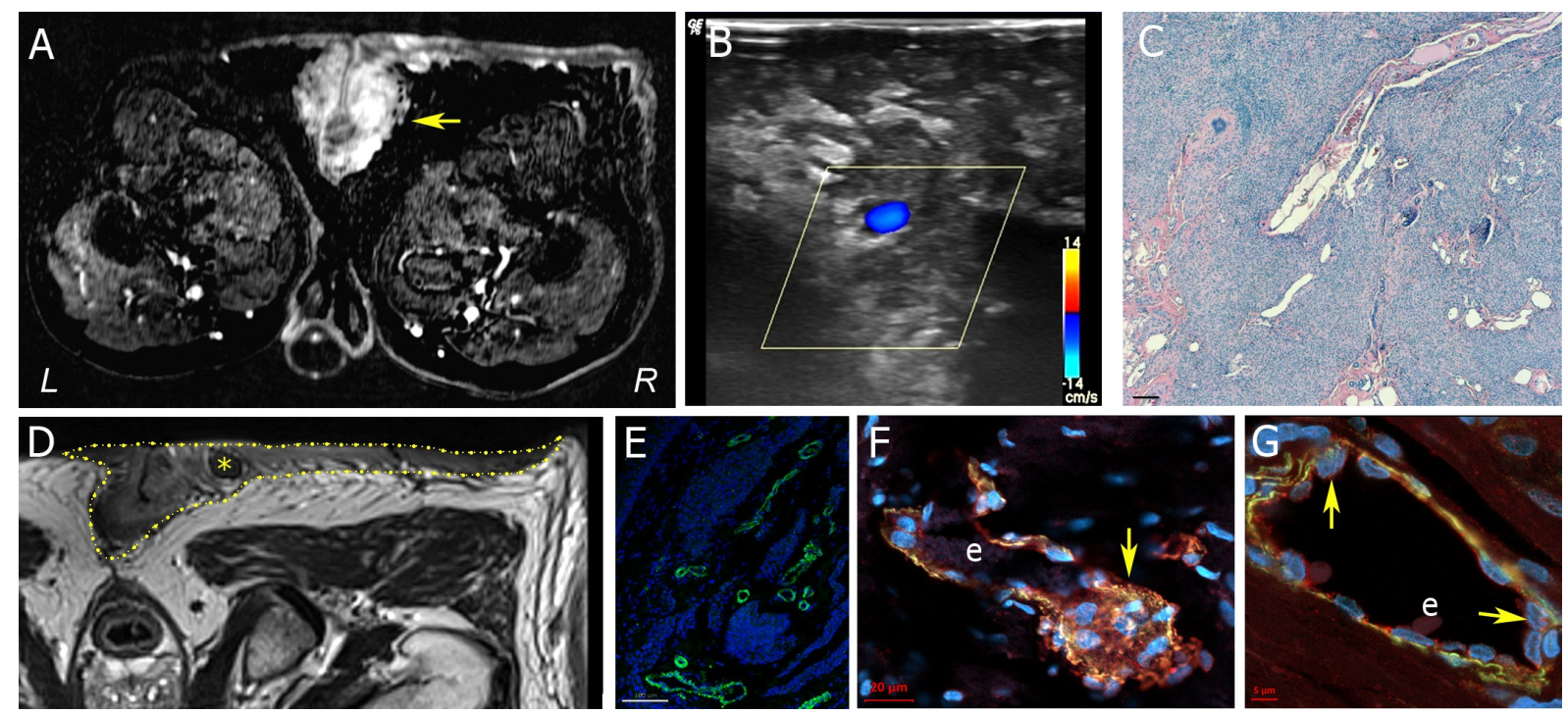